\title{
Predicting suitable habitat of the Chinese monal (Lophophorus lhuysii) using ecological niche modeling in the Qionglai Mountains, China
}

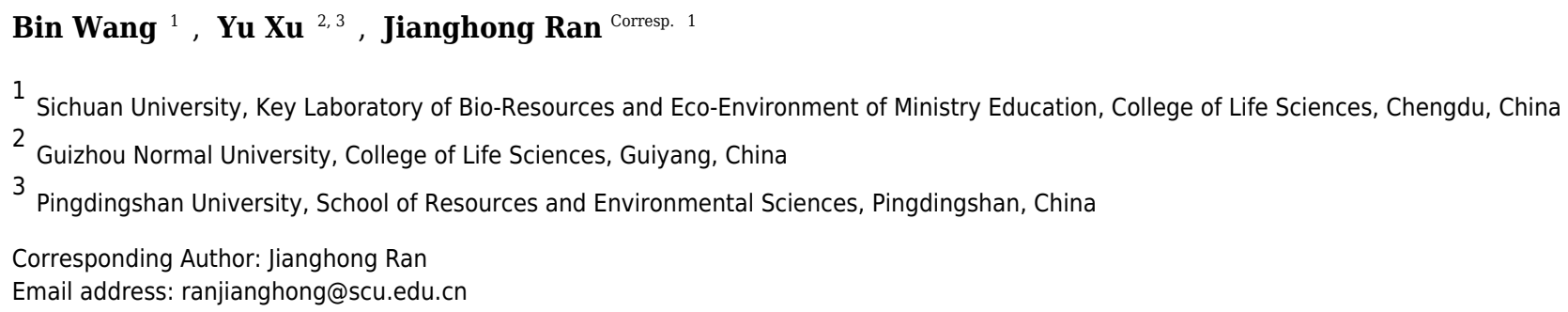

Understanding the distribution and the extent of suitable habitats is crucial for wildlife conservation and management. Knowledge is limited regarding the natural habitats of the Chinese monal (Lophophorus Ihuysii), which is a vulnerable Galliform species endemic to the high-montane areas of southwest China and a good candidate for being an umbrella species in the Qionglai Mountains. Using ecological niche modeling, we predicted current potential suitable habitats for the Chinese monal in the Qionglai Mountains with 64 presence points collected between 2005 and 2015. Suitable habitats of the Chinese monal were associated with about $31 \mathrm{~mm}$ precipitation of the driest quarter, about $15^{\circ} \mathrm{C}$ of maximum temperature of the warmest month, and far from the nearest human residential locations (> 5,000 $\mathrm{m}$ ). The predicted suitable habitats of the Chinese monal covered an area of $2,490 \mathrm{~km}^{2}$, approximately $9.48 \%$ of the Qionglai Mountains, and was highly fragmented. $54.78 \%$ of the suitable habitats were under the protection of existing nature reserves and two conservation gaps were found. Based on these results, we provide four suggestions for the conservation management of the Chinese monal: (1) ad hoc surveys targeting potential suitable habitats to determine species occurrence, (2) more ecological studies regarding its dispersal capacity, (3) establishment of more corridors and green bridges across roads for facilitating species movement or dispersal, and (4) minimization of local disturbances. 
1 Predicting suitable habitat of the Chinese monal (Lophophorus lhuysii) using ecological

2 niche modeling in the Qionglai Mountains, China

3 Bin Wang ${ }^{\text {a\#\#}, ~ Y u ~ X u ~}{ }^{\text {bc\#}, \text { Jianghong Ran }}{ }^{\text {a* }}$

$4{ }^{a}$ Key Laboratory of Bio-Resources and Eco-Environment of Ministry Education, College of Life

5 Sciences, Sichuan University, Chengdu 610064, China.

$6 \quad{ }^{b}$ College of Life Sciences, Guizhou Normal University, Guiyang 550001, China.

7 c School of Resources and Environmental Sciences, Pingdingshan University, Pingdingshan,

8 Henan Province 467000, China.

9

10 \# Authors contributed equally to this work.

11 * Corresponding author. E-mail: ranjianghong@scu.edu.cn; Tel.: +86-13308026600 


\section{ABSTRACT}

13 Understanding the distribution and the extent of suitable habitats is crucial for wildlife

14 conservation and management. Knowledge is limited regarding the natural habitats of the Chinese

15 monal (Lophophorus lhuysii), which is a vulnerable Galliform species endemic to the high-

16 montane areas of southwest China and a good candidate for being an umbrella species in the

17 Qionglai Mountains. Using ecological niche modeling, we predicted current potential suitable

18 habitats for the Chinese monal in the Qionglai Mountains with 64 presence points collected

19 between 2005 and 2015. Suitable habitats of the Chinese monal were associated with about $31 \mathrm{~mm}$

20 precipitation of the driest quarter, about $15^{\circ} \mathrm{C}$ of maximum temperature of the warmest month,

21 and far from the nearest human residential locations $(>5,000 \mathrm{~m})$. The predicted suitable habitats

22 of the Chinese monal covered an area of $2,490 \mathrm{~km}^{2}$, approximately $9.48 \%$ of the Qionglai

23 Mountains, and was highly fragmented. 54.78\% of the suitable habitats were under the protection

24 of existing nature reserves and two conservation gaps were found. Based on these results, we provide four suggestions for the conservation management of the Chinese monal: (1) ad hoc surveys targeting potential suitable habitats to determine species occurrence, (2) more ecological studies regarding its dispersal capacity, (3) establishment of more corridors and green bridges across roads for facilitating species movement or dispersal, and (4) minimization of local disturbances. 


\section{INTRODUCTION}

32 Understanding the distribution of suitable habitats and its influencing factors are crucial for

wildlife conservation and management (Austin 2002). Ecological niche models have developed as excellent tools for predicting habitat distribution of species that are difficult to investigate (Peterson et al. 2002, Mota-Vargas et al. 2013), because they can predict the distribution of species' habitats at a large spatial scale based on species presence data and environmental variables, without the need for extensive surveys and detailed descriptions of physiological and behavioral characteristics (Morrison et al. 2012). In particular, MaxEnt, a presence-only modeling approach based on the maximum entropy principle (Phillips et al. 2006), outperforms other models in prediction accuracy (Elith et al. 2006, Phillips et al. 2006), transferability (Tuanmu et al. 2011), and performance with small sample sizes (Pearson et al. 2007, Costa et al. 2010). It offers great potential for addressing endangered and poorly known bird species with scarce occurrence data (e.g. Botero-Delgadillo et al. 2012, Marcondes et al. 2014, Tobón-sampedro et al. 2015).

The Chinese monal (Lophophorus lhuysii) is the largest Galliform species (with a mean length of $76 \mathrm{~cm}$ and a mean weight of $3.18 \mathrm{~kg}$ ) distributed in high-montane regions, mainly inhabiting subalpine scrubs, as well as subalpine and alpine meadows at an elevation of 3,000-4,900 m (MacKinnon et al. 2000, Madge et al. 2002). This species is endemic to southwest China, and is found primarily in southeast Gansu, southeast Qinghai, western Sichuan, and northwest Yunnan (Lei and Lu 2006, Lu 2015). It has been listed on appendix I of CITES since 1975 (CITES 2016) and classified as a vulnerable species on the IUCN red list since 1994 (IUCN 2015). In 1989, the Chinese government started to legally protect the species as a first-class, nationally-protected 
52 wildlife species (Checklist of Wild Animals of National Priority Protection 1989). Recently, the

53 Chinese monal was identified as one of the endemic bird species in China with the highest

54 conservation values in terms of phylogenetic diversity (Chen 2013). Its population size, however,

55 remains small (10,000-25,000 individuals in total, BirdLife International 2015) and is inferred to

56 be in a state of continuous decline because of illegal hunting and on-going habitat degradation and

57 fragmentation (BirdLife International 2015). It is therefore necessary to establish effective conservation programs targeting the Chinese monal. and inaccessible habitats of the species make it difficult to survey the natural populations. Most of the previous studies were conducted in the late twentieth century and only provided simple descriptions of habitat use (Ma 1989, Zhang 1995), population density and structure (He and Lu 1985, Long et al. 1998), breeding ecology (He et al. 1986), activity pattern (Ma 1988), and feeding habits (Lu et al. 1986). There has not been a quantitative analysis of the natural habitats of the environmental variables, to predict the current potential suitable habitats for the Chinese monal in 
73 the Qionglai Mountains. Our objectives were to (1) delineate the distribution of suitable habitats

74 of the Chinese monal, (2) identify critical environmental factors influencing the species' habitat

75 suitability, (3) compare the prediction with existing nature reserve network and provide

76 conservation suggestions based on the results.

77 MATERIALS \& METHODS

78

\section{Study area}

The Qionglai Mountains are the easternmost portion of the Hengduan Mountains, extending approximately $250 \mathrm{~km}$ from north to south at the center of Sichuan Province, China (E: $102^{\circ} 01^{\prime}-$ $103^{\circ} 46^{\prime}, \mathrm{N}: 2^{\circ} 27^{\prime}-31^{\circ} 55^{\prime}$; Figure 1). The area covers $26,258 \mathrm{~km}^{2}$ and incorporates 12 counties, including Lixian, Xiaojin, Baoxing, Dayi, Lushan, Qionglai, and Tianquan. The areas west of the Min River in Wenchuan, Dujiangyan and Chongzhou counties are also included in the Qionglai Mountains (the east side of the River belongs to the Minshan Mountains). The areas east of the Dadu River in Luding and Kangding counties are also included in the Qionglai Mountains (the west sides of the River belong to the Daxueshan Mountains). Elevation ranges from $450 \mathrm{~m}$ in the Sichuan Basin to $6,250 \mathrm{~m}$ at the Siguniang Mountain peak. The subtropical monsoon climate predominates the region. There are diverse ecosystems and vegetation types, with many rare and endangered wildlife species, such as the giant panda (Ailuropoda melanoleuca), golden snubnosed monkey (Rhinopithecus roxellanae), snow leopard (Panthera unica), takin (Budorcas taxicolor), and dove tree (Davidia involucrate) (Hu 2001).

\section{Presence data}

In total, we gathered 103 current (2005-2015) presence records of the Chinese monal (Table 
94 S1), including sightings, callings, feces, and feathers. The majority (86.4\%) of the records was

95 from field surveys in recent years, including the authors' filed survey records, sympatric animal

96 database of the fourth national survey on giant panda, and biodiversity monitoring data from nature

97 reserves; the remaining data was from published literatures and network databases (for details, see

Table 1). To insure spatial accuracy, we only kept presence points with accuracies to three decimal places of the coordinates. To avoid overfitting the model, we generated a $1 \mathrm{~km}^{2}$ buffer around each presence point and randomly selected one if the buffers overlap, as this area approximates the minimum home range size maintained by the Chinese monal ( $\mathrm{He}$ and $\mathrm{Lu}$ 1985). Finally, 64 remained presence points with geographic coordinates were used to build the ecological niche model (Figure 1).

\section{Environmental data}

42 environmental variables (Table S2) summarizing five groups (bioclimatic data, vegetation, phenological metrics, topographical attributes, and human impacts) potentially related to habitat suitability of the Chinese monal were selected as candidate variables. We included 19 bioclimatic variables from WorldClim 1.4 (http://www.worldclim.org/), which were interpolated based on a large number of weather stations all over the world, integrating the effects of latitude, longitude, and elevation (Hijmans et al. 2005). Bioclimatic data were frequently used in habitat modeling due to direct effects on species distribution (Guisan and Zimmermann 2000). Vegetation and phenology-related variables were derived from moderate resolution imaging spectroradiometer

113 (MODIS) remotely sensed data from LP DAAC (https://lpdaac.usgs.gov/). The International 114 Geosphere-Biosphere Programme (IGBP) classification of land cover within MCD12Q1 2014 
115

116

product was used as a categorical variable of vegetation type (Loveland and Belward 1997). This classification was derived from yearly MODIS data and 1860 training sites observations distributed across the Earth's land areas (Friedl et al. 2010). We downloaded a time series of MOD13Q1 16-day enhanced vegetation index (EVI) product over a three year period from 2013 to 2015 (23 layers per year). To reduce the potential noise caused by cloud remnants, we reconstructed a clean and smooth EVI time series employing an adaptive Savitzky-Golay filter and then generated 15 phenological metrics using TIMESAT 3.2 (Jönsson and Eklundh 2002, 2004). These EVI derived metrics strongly correlate with vegetation primary productivity and its seasonality (Jönsson and Eklundh 2002, Rahman et al. 2005, Alcaraz-Segura et al. 2013), and could improve the performance of species habitat modeling (Requena-Mullor et al. 2014). The topographical attributes included elevation, slope, aspect, and distance to rivers. Slope and aspect were extracted from an ASTER GDEM V2 $30 \mathrm{~m}$ resolution digital elevation model (DEM; http://www.gscloud.cn/), using Surface Analyst Tool of ArcGIS 10.2 (ESRI, Redlands, CA, USA). Aspect was recalculated as the absolute value of actual degree minus $180^{\circ}$, representing how close the slope was to the adret facing the sun (Kalkhan 2011). We produced a layer of distance to the nearest perennial river using the Euclidean Distance Tool of ArcGIS. Variables regarding human impacts included Euclidean distance to residential locations (villages and rural settlements) and to roads, and human influence index (HII). HII layer was downloaded from Last of the Wild (Data Version 2, 2005) (http://sedac.ciesin.columbia.edu/), representing anthropogenic impacts spanning 1995-2004 that were calculated by integrating the data including human population pressure (population density), human land use (built-up areas, nighttime lights, land use, and land cover), 
136 137

and human accessibility (coastlines, roads, railroads, and navigable rivers). The basic vector layers of rivers, roads, and residential locations were provided by National Geomatics Center of China (NGCC). Each variable was projected to the UTM zone $48 \mathrm{~N}$ coordinate system, and resampled to the same pixel size as the EVI layers (about $250 \mathrm{~m}$ ) using bilinear interpolation, except for the categorical land cover that was resampled using nearest neighbor assignment.

\section{Model procedure}

We used MaxEnt to generate the habitat suitability model of the Chinese monal (MaxEnt 3.3.3k, http://www.cs.princeton.edu/ schapire/maxent/). Ecological niche models with inappropriately complex variables might be oversized, overfitted or redundant (Parolo et al. 2008, Swanepoel et al. 2013). To increase abilities in building high accuracy predictions and in identifying the critical predictors constraining the species' distribution, we implemented an optimized selection of 42 environmental variables based on sample-size-corrected Akaike information criteria (AICc) (Akaike 1974, Warren and Seifert 2011, Warren et al. 2014). Firstly, we built a MaxEnt model with the full set of 42 variables and removed variables with contribution $<1 \%$ or had Pearson's correlation coefficients $>|0.7|$ with the highest contributed variable; then the retained variables were used to build a new model, and the variables with low contribution $(<1 \%)$ or high correlation coefficients (absolute values $>0.7$ ) with the second highest contributed variable were removed again; finally, a set of models with different set of variables were produced after repeating this process, and AICc value was calculated for each model based on codes proposed by Warren et al. (2010). The model with the lowest AICc was considered to have the most appropriate complexity (Warren and Seifert 2011, Jueterbock et al. 2016), thus the variables included in this model were 
157 selected to build the final model for Chinese monal habitat. The optimized variable selection was

158 processed in R 3.2.2 (R Development Core Team 2015) with package "MaxentVariableSelection"

159 (Jueterbock 2015, Jueterbock et al. 2016).

160 The regularization multiplier, maximum number of background points, maximum iterations,

161 and convergence threshold were set as default values, since these settings have been found to

162 achieve good performances (Phillips and Dudík 2008). To produce stable results, we ran 20

163 replicate bootstrap procedures for the final model. Each replicate used a randomly selected dataset

164 of $75 \%$ training data and $25 \%$ test data. The built-in functions: contribution of variables, response

165 curves, and jackknife test, were used to analyze the relative importance of each variable in

166 modeling, and their relation with the habitat suitability. We used an average output grid of 20

167 replicates as the final model prediction, with a logistic habitat suitability index ranging from the

168 lowest " 0 " to the highest " 1. ."

169 Model performance was evaluated using three different measures, including area under the

receiver operating characteristic curve (AUC), Cohen's maximized Kappa, and the true skill

statistic (TSS). All three measures are calculated based on specificity and sensitivity of the

predictive model. Specificity and sensitivity represent the success rate for classifying absences and

presences, respectively. AUC is a threshold-independent evaluation measure obtained by plotting

sensitivity against 1-specificity (Fielding and Bell 1997). We used the built-in function of MaxEnt

program to produce the mean AUC values of the 20 replicates. The model accuracy can be judged

176 as excellent if $\mathrm{AUC}>0.9$, good if $0.9>\mathrm{AUC}>0.8$, fair if $0.8>\mathrm{AUC}>0.7$, poor if $0.7>\mathrm{AUC}>$

0.6 , and failed if $0.6>$ AUC $>0.5$ (Swets 1988). 
Kappa and TSS are threshold-dependent indices that measure the agreement between

predictions and known occurrences (presences and absences) at different binary thresholds. Kappa index is obtained by plotting sensitivity and specificity against different thresholds (Cohen 1960), while TSS equals sensitivity + specificity -1 (Allouche et al. 2006). Another difference is that Kappa index responds to species prevalence whereas TSS does not (Allouche et al. 2006). In this study, we used maximized values of Kappa and TSS at their own optimal thresholds to evaluate model performance. The standards for judging model performance are: excellent if Kappa $>0.75$, good if $0.75>$ Kappa $>0.4$, and poor if Kappa $<0.4$ (Araújo et al. 2005); while good to excellent

if TSS $>0.8$, useful if $0.8>\mathrm{TSS}>0.5$, and poor if $0.5>\mathrm{TSS}>0.2$ (Coetzee et al. 2009). Since

these two indices require the use of absence data, 200 additional pseudo-absence points were

generated within the study region. These pseudo-absence points were randomly located outside

the $1 \mathrm{~km}$ buffers of observed presence points for Chinese monals. The threshold-dependent

statistics were analyzed in R 3.2.2 (R Development Core Team 2015) with package

"PresenceAbsence" (Freeman and Moisen 2008).

192

193

194

195

196

197

\section{Habitat analysis}

For further analysis, we applied a threshold that maximizes the TSS for transforming the model prediction with a continuous habitat suitability index to a binary suitable/unsuitable map. Maximum TSS is a promising threshold criterion when only species presence data are available, outperforming many other criterions in most cases (Liu et al. 2005, Jiménez-Valverde and Lobo 2007, Liu et al. 2013). We estimated total suitable habitat area of the Chinese monal in the Qionglai Mountains and areas harboured in counties and nature reserves, respectively. 
199

200

201

202

203

204

205

206

207

208

209

210

211

212

213

214

215

216

217

218

219

\section{RESULTS}

Optimized variable selection showed that the model with the lowest AICc was built with: maximum temperature of the warmest month (bioclim5), precipitation of the driest quarter (bioclim17), annual maximum of EVI (evi maximum), base level values of EVI (evi base level), slope, and distances to residential locations (d_resident) and to roads (d_road) (Table S3 and S4). The seven predictors were therefore selected for the final MaxEnt modeling. We obtained average values of model evaluation indices after 20 replicates: training $\mathrm{AUC}=0.966$, test $\mathrm{AUC}=0.953$, maximum Kappa $=0.813$, and maximum TSS $=0.882$. High scores of model evaluation indices, both the threshold-independent and threshold-dependent, indicated that the habitat suitability model produced by MaxEnt performed excellently (Manel et al. 2001, Araújo et al. 2005).

\section{Relevant variables}

Evaluation of percent contribution of each variable to the model illustrated that three predictors had over $10 \%$ relative contribution to the habitat suitability model of the Chinese monal, contributing 78\% collectively (Table 2). Precipitation of the driest quarter (bioclim17) made the largest contribution, followed by maximum temperature of the warmest month (bioclim5) and distance to the nearest residential locations. Similarly, these three predictors received the highest AUC values when used in isolation in the jackknife test (Table 2), indicating they are better at discriminating suitable from non-suitable habitat as compared with the other variables. The response of logistic probability of monal occurrence on the two critical climatic predictors were both unimodal, that the probabilities were at the peak at $31 \mathrm{~mm}$ for precipitation of the driest quarter and at $15{ }^{\circ} \mathrm{C}$ for maximum temperature of the warmest month (Figure 2 a \& b). The 
response curve also showed that monals were more likely to occur at sites further away $(>5,000$

m) from the nearest human residential locations (Figure $2 \mathrm{c}$ ).

222

223

224

225

226

227

228

229

230

231

232

\section{Habitat status}

We created a binary suitable/unsuitable habitat map after applying the maximum TSS threshold (where habitat suitable index $=0.208$ ). The suitable habitats for the Chinese monal covered an area of 2,490 $\mathrm{km}^{2}$, corresponding to $9.48 \%$ of the entire Qionglai Mountains region. The majority of suitable habitats for the Chinese monal distributed in the central mountain regions, mainly stretching along the boundaries of Lixian-Wenchuan, Wenchuan-Baoxing, Xiaojin-Baoxing, and Baoxing-Tianquan (Figure 3, Table 3). Ten existing nature reserves are located in the Qionglai Mountains, covering over a quarter of the entire region. Over $50 \%$ of the suitable monal habitats were situated within nature reserves. Wolong Nature Reserve provided the largest area of suitable habitats for the Chinese monal, while Heishuihe, Labahe, and Fengtongzhai Nature Reserve also had high proportions of suitable habitat (Table 4). Two general regions with large areas of potential suitable habitat were outside of any nature reserves: one in the northern region of Lixian County, and the other in northwest Baoxing County (Figure 3).

\section{DISCUSSION}

Our study represents the first attempt at predicting the suitable habitat of the Chinese monal. Variable analysis revealed that bioclimatic variables were the most influential predictors on the habitat suitability of the Chinese monal. Higher habitat suitability was constrained in narrow ranges of both precipitation of the driest quarter and maximum temperature of the warmest month, suggesting that Chinese monal was highly sensitive to climate under extreme periods. The monals 
241

242

243

244

246

247

248

249

250

251

252

253

254

255

256

257

258

259

260

261

appeared to prefer habitats far away from residential locations, suggesting human disturbance as a crucial pressure for the species. Although roads represent remarkable sources of disturbance to wildlife that could lead to road-kill (Mumme et al. 2000) and barrier effect (Shepard et al. 2008), the impact of roads was relatively weak in our niche model (Table 2). It is likely that a greater part of occurrence records were sampled in more easily accessible sites in proximity to roads (Figure 1), and such a sampling bias had decreased the importance of roads disturbance in the model. Despite the sampling bias towards roads, we found an relation that habitat suitability increased with increasing distance from roads in the niche model predictions (Figure $2 \mathrm{~d}$ ). As an explanation, we suggest that our predictive habitat suitability was more sensitive to bioclimatic conditions than to human disturbance; sites with bioclimatic conditions preferred by the Chinese monal might be infrequently crossed by roads.

The predicted suitable habitats for the Chinese monal were highly fragmented. Specialized niche requirements (i.e. narrow climate preferences) constrained their suitable habitats to subalpine and alpine regions. High mountain ridges and deep valleys throughout the Qionglai Mountains separated the suitable haibtats into small and isolated patches, especially for those distributed in the north of Lixian County, south of Baoxing County, and the boundary area of Lixian-XiaojinWenchuan County (Figure 3). As a strong disturbance, human residential areas further restricted and separated the suitable habitats. The fragmentation might have negative effects on the Chinese monal, which has low dispersal ability (With and Crist 1995), reducing the probability of genetic exchange (Höglund et al. 2011) and colonizing suitable empty patches (Stamps et al. 1987) by increasing the resistance to individual movement between isolated habitat patches. 

yaks. Grazing could lead to direct disturbance, accelerating habitat degradation and fragmentation, 264 and increasing the probability of poaching ( $\mathrm{Lu}$ et al. 1986, Ma 1988, Long et al. 1998). Additionally, gathering of herbs for use in traditional Chinese medicine in spring and summer, especially the collection of Fritillaria spp., an important food source of the Chinese monal, could result in a reduction of food abundance and thus a direct disturbance to the Chinese monal (Fuller 2000, Lu 2015). Our study, however, failed to incorporate these remarkable local threats into modeling due to the lack of data. If grazing and herb gathering are considered, the actual suitable monal habitat might be even smaller, more fragmented, and more variable than our prediction. the species may be at greater risk than has previously been considered. As a typical high-montane species with large home range, the Chinese monal has the potential to serve as an umbrella or flagship species for high-montane ecosystems. Conservation of these ecosystems will likely contribute to the maintenance of regional biodiversity, at least for the montane Galliformes (Roberge and Angelstam 2004, Rowland et al. 2006, McGowan et al. 2009). Based on our results, we have several conservation suggestions targeting the Chinese monal. Our prediction could guide future field surveys for locating new populations in the areas that were predicted to be suitable habitat but lack investigation (Raxworthy et al. 2003, Menon et al. 2010). The large and wellconnected habitat patches distributed in the boundary area of Wenchuan, Baoxing, Lushan, and 
283 boundary of Baoxing County is unprotected by any nature reserves and lacks systematic survey

284 (Figure 3). Similarly, large ribbon-like patches of suitable habitats in northeast of Lixian County

285 and north of Wenchuan County was also lacking protection and survey (Figure 3). Our first

286 suggestion, therefore, is to conduct ad hoc surveys for determining the actual occurrence of

287 Chinese monal in these two areas. If there are indeed some populations in these two regions, we suggest that new nature reserves should be designated in order to fill these two obvious conservation gaps. The second suggestion is to study the dispersal capacity of the Chinese monal for further assessing habitat quality and fragmentation. Such ecological knowledge could be helpful for determining the actual distribution of animals in relation to the distribution of suitable environmental habitats (Pulliam 2000, Lu et al. 2012). For instance, it will be useful to determine whether the Zagunao river valley is a geographic barrier that Chinese monals cannot cross through, and whether gene flow can occur between the monal populations isolated in the south and north of Baoxing County (Figure 3).

Although human disturbance appeared to be a crucial pressure for Chinese monals (He et al. 1986), we found that Chinese monals did not respond avoiding roads. For instance, during our survey at Wenchuan in 2015, we observed that two Chinese monal pairs, almost at a daily bases, crossed provincial road 303 through the top of the Huayan tunnel (E102 $58^{\prime}, \mathrm{N}_{30}^{\circ} 51^{\prime}$; Figure 1), a well-known location for shooting Chinese monal among wildlife photographers. Huayan tunnel has a length of $570 \mathrm{~m}$, and the large area of natural shrub and meadow preserved on its top serves as a corridor for the monals. However, this does not mean that roads are not a significant threat for the species, as road-kill of Galliformes are not uncommon (Clevenger et al. 2003, D'Amico et al. 
304 305

306

307

308

309

310

311

312

313

314

315

316

317

318

319

320

321

322

323

324

2015). Our third suggestion, therefore, is to build more corridors and green bridges across roads to facilitate road-crossing or dispersal by Chinese monals.

For the purpose of 'game food', Chinese monals had been often poached by local people before 1980s, which was considered as the main cause of a substantial decline of the species (He et al. 1986, Lu et al. 1986, Long et al. 1998, Lei and Lu 2006). Unfortunately, we found self-made traps for capturing monals and other Galliformes during our surveys, both inside and outside nature reserves, suggesting that poaching is still continuing nowadays. Even though we found little evidence of human impact on monal habitat distribution, our field observation suggested that illegal hunting potentially threaten survival of the Chinese monals and their sympatric Galliform species. Moreover, other short-term and seasonal local disturbance such as yak grazing and herb collection could increase the probability of poaching (Lu et al. 1986, Ma 1988, Long et al. 1998). Therefore, our fourth suggestion is to limit local disturbances, such as poaching, yak grazing, and herb collection, for maintaining existing populations and habitats of the Chinese monal as well as other montane Galliformes.

\section{CONCLUSION}

This study used the ecological niche modeling approach to predict current suitable habitat of the Chinese monal in Qionglai Mountains. Their suitable habitat was associated with about $31 \mathrm{~mm}$ precipitation of the driest quarter, about $15^{\circ} \mathrm{C}$ of maximum temperature of the warmest month, and far from the nearest human residential locations $(>5,000 \mathrm{~m})$. The predicted suitable habitats of the Chinese monal was highly fragmented covering an area of $2,490 \mathrm{~km}^{2} .54 .78 \%$ of suitable habitat was under the protection of existing nature reserve network, but there were obvious 
325

326

327

328

329

330

331

332

conservation gaps as two regions with large area of well-connected suitable habitat were out of any nature reserve. Finally, this study provide conservation management suggestions in terms of ad hoc surveys targeting potential suitable habitats to determine occurrence of Chinese monals, more ecological studies regarding its dispersal capacity, establishment of more corridors and green bridges across roads in suitable habitats and limitation of local disturbances such as poaching, yak grazing, and herb collection.

\section{ACKNOWLEDGEMENTS}

We thank Heishuihe Nature Reserve and Labahe Nature Reserve for providing monitoring data, and Fengtongzhai National Nature Reserve, Wolong National Nature Reserve, Anzihe Nature

Reserve for the supports provided during the fieldworks. We are grateful to Qiang Dai and Tingting Yan for their recommendations on methodology, and Liang Dou, Nan Yang, Xiang Yu, Bo Zhang for their assistance in the fieldworks. Zhengyang Wang from Harvard University helped to correct the English writing of the manuscript.

\section{REFERENCES}

Akaike H. 1974. A new look at the statistical model identification. IEEE Transactions on Automatic Control 19:716-723.

Alcaraz-Segura D, Paruelo JM, Epstein HE, Cabello J. 2013. Environmental and human controls of ecosystem functional diversity in temperate South America. Remote Sensing 5:127-154.

Allouche O, Tsoar A, Kadmon R. 2006. Assessing the accuracy of species distribution models: prevalence, kappa and the true skill statistic (TSS). Journal of Applied Ecology 43:12231232. 
346

347

348

349

350

351

352

353

354

355

356

357

358

359

360

361

362

363

364

365

366

Araújo MB, Pearson RG, Thuiller W, Erhard M. 2005. Validation of species-climate impact models under climate change. Global Change Biology 11:1504-1513.

Austin MP. 2002. Spatial prediction of species distribution: an interface between ecological theory and statistical modelling. Ecological modelling 157:101-118.

BirdLife International. 2015. Species factsheet: Chinese monal Lophophorus lhuysii. Available at http://www.birdlife.org/ (accessed November 2015).

Botero-Delgadillo E, Páez CA, Bayly N. 2012. Biogeography and conservation of Andean and Trans-Andean populations of Pyrrhura parakeets in Colombia: Modelling geographic distributions to identify independent conservation units. Bird Conservation International 22:445-461.

Chen YH. 2013. Conservation priority for endemic birds of mainland China based on a phylogenetic framework. Chinese Birds 4:248-253.

Clevenger AP, Chruszcz B, Gunson KE. 2003. Spatial patterns and factors influencing small vertebrate fauna road-kill aggregations. Biological Conservation 109:15-26.

Coetzee BWT, Robertson MP, Erasmus BFN, Van Rensburg BJ, Thuiller W. 2009. Ensemble models predict Important Bird Areas in southern Africa will become less effective for conserving endemic birds under climate change. Global Ecology and Biogeography 18:701-710.

Cohen J. 1960. A coefficient of agreement for nominal scales. Educational and Psychological Measurement 20:37-46.

Costa GC, Nogueira C, Machado RB, Colli GR. 2010. Sampling bias and the use of ecological 
367

368

369

niche modeling in conservation planning: a field evaluation in a biodiversity hotspot. Biodiversity and Conservation 19:883-899.

D'Amico M, Román J, Reyes LDL, Revilla E. 2015. Vertebrate road-kill patterns in Mediterranean habitats: Who, when and where. Biological Conservation 191:234-242.

Elith J, Graham CH, Anderson RP, Dudík M, Ferrier S, Guisan AJ, Hijmans R, Huettmann FR, Leathwick J, Lehmann A, Li JG, Lohmann L. 2006. Novel methods improve prediction of species' distributions from occurrence data. Ecography 29:129-151.

ESRI. 2013. ArcGIS 10.2 desktop. Environmental Systems Research Institute, Redlands, CA, USA.

Fielding AH, Bell JF. 1997. A review of methods for the assessment of prediction errors in conservation presence/absence models. Environmental Conservation 24:38-49.

Freeman EA, Moisen G. 2008. PresenceAbsence: An R package for presence-absence model analysis. Journal of Statistical Software 23:1-31. Available at https://cran.rproject.org/web/packages/PresenceAbsence/index.html.

Friedl MA, Sulla-Menashe D, Tan B, Schneider A, Ramankutty N, Sibley A, Huang X. 2010. MODIS Collection 5 global land cover: Algorithm refinements and characterization of new datasets. Remote Sensing of Environment 114:168-182.

Fuller RA. 2000. Pheasants: status survey and conservation action plan 2000-2004. IUCN.

Guisan A, Zimmermann NE. 2000. Predictive habitat distribution models in ecology. Ecological modelling 135:147-186.

Höglund J, Larsson JK, Corrales C, Santafé G, Baines D, Segelbacher G. 2011. Genetic structure 
388

389

390

391

392

393

394

395

396

397

398

399

400

401

402

403

404

405

406

407

408

among black grouse in Britain: implications for designing conservation units. Animal Conservation 14:400-408.

He FQ, Lu T.C. 1985. Ecology of the Chinese monal in winter. Zoological Research 4:345-352. (in Chinese)

He FQ, Lu TC, Lu CL, Cui XZ. 1986. Study on the breeding ecology of the Chinese monal. Acta Ecologica Sinica 2:186-192. (in Chinese)

Hijmans RJ, Cameron SE, Parra JL, Jones PG, Jarvis A. 2005. Very high resolution interpolated climate surfaces for global land areas. International journal of climatology 25:1965-1978.

Hu JC. 2001. Research on the giant panda. Shanghai Publishing House of Science and Technology, Shanghai. (in Chinese)

IUCN. 2015. IUCN Red List of Threatened Species. Available at http://www.iucnredlist.org/ (accessed November 2015).

Jiménez-Valverde A, Lobo JM. 2007. Threshold criteria for conversion of probability of species presence to either-or presence-absence. Acta Oecologica 31:361-369.

Jönsson P, Eklundh L. 2002. Seasonality extraction by function fitting to time-series of satellite sensor data. IEEE Transactions on Geoscience and Remote Sensing 40:1824-1832.

Jönsson P, Eklundh L. 2004. Timesat - a program for analyzing time-series of satellite sensor data. Computers and Geosciences 30:833 - 845 .

Jueterbock A. 2015. R package MaxentVariableSelection: selecting the best set of relevant environmental variables along with the optimal regularization multiplier for Maxent niche modeling. Available at 
https://cran.rproject.org/web/packages/MaxentVariableSelection/index.html.

410 Jueterbock A, Smolina I, Coyer JA, Hoarau G. 2016. The fate of the Arctic seaweed Fucus 411 distichus under climate change: an ecological niche modeling approach. Ecology and Evolution 6:1712-1724.

413 Kalkhan MA. 2011. Spatial Statistics: GeoSpatial Information Modeling and Thematic Mapping. CRC Press, New York. 2016). prediction of species distributions. Ecography 28:385-393.

Liu C, White M, Newell G. 2013. Selecting thresholds for the prediction of species occurrence Zoology 17:104-105. (in Chinese) results. International Journal of Remote Sensing 18:3289-3295. with presence-only data. Journal of Biogeography 40:778-789.

Long TL, Shao KQ, Guo G, Cheng CY, Zou XY, Landel H, Rimlinger D, Zhou FL. 1998. Field tracking and ecological observation of the Chinese monal in winter. Sichuan Journal of

Loveland TR, Belward AS. 1997. The IGBP-DIS global 1km land cover data set, DISCover: first 

Conservation 152:102-109.

432

433

434

435

436

437

438

439

440

441

442

443

444

445

446

447

448

449

450 in China. Higher Education Press, Beijing. (in Chinese)

Lu TC, Liu RS, He FQ, Lu CL. 1986. Ecological studies on Chinese monal. Acta Zoologica Sinica 3:273-279. (in Chinese)

Ma GY. 1988. Observation on the Chinese monal in Gansu Province. Sichuan Journal of Zoology 7:41-42. (in Chinese)

Ma GY. 1989. Distribution and ecological observation of the Chinese monal in Gansu Province. Journal of Tianshui Normal University 1:101-104. (in Chinese)

MacKinnon JR, Phillipps K, He FQ. 2000. A field guide to the birds of China. Oxford University Press, Oxford.

Madge S, McGowan PJ, Kirwan GM. 2002. Pheasants, partridges and grouse: a guide to the pheasants, partridges, quails, grouse, guineafowl, buttonquails and sandgrouse of the world. Christopher Helm, London.

Manel S, Williams HC, Ormerod SJ. 2001. Evaluating presence-absence models in ecology: the need to account for prevalence. Journal of Applied Ecology 38:921-931.

Marcondes RS, Del-Rio G, Rego MA, Silveira LF. 2014. Geographic and seasonal distribution of a little-known Brazilian endemic rail (Aramides mangle) inferred from ocurrence records and ecological niche modeling. The Wilson Journal of Ornithology 126:663-672.

McGowan PJ, Zhang YY, Zhang ZW. 2009. Galliformes-barometers of the state of applied 
ecology and wildlife conservation in China. Journal of Applied Ecology 46:524-526.

452

453

454

455

456

457

458

459

460

461

462

463

464

465

466

467

468

469

470

471

Menon S, Choudhury BI, Khan ML, Peterson AT. 2010. Ecological niche modeling and local knowledge predict new populations of Gymnocladus assamicus, a critically endangered tree species. Endangered Species Research 11: 175-181.

Ministry of Forestry of People's Republic of China, Ministry of Agriculture of People's Republic of China. 1989. Checklist of Wild Animals of National Priority Protection.

Morrison ML, Marcot B, Mannan W. 2012. Wildlife-habitat relationships: concepts and applications. Island Press, Washington, DC.

Mota-Vargas C, Rojas-Soto OR, Lara C, Castillo-Guevara C, Ballesteros-Barrera C. 2013. Geographic and ecological analysis of the bearded wood partridge Dendrortyx barbatus: some insights on its conservation status. Bird Conservation International 23:371-385.

Mumme RL, Schoech SJ, Woolfenden GE, Fitzpatrick JW. 2000. Life and death in the fast lane: demographic consequences of road mortality in the florida scrub-jay. Conservation Biology 14: 501-512.

Mittermeier RA, Turner WR, Larsen FW, Brooks TM, Gascon C. 2011. Global biodiversity conservation: the critical role of hotspots. Pages 3-22 in: Zachos FE and Habel JC, editor. Biodiversity hotspots: Distribution and protection of priority conservation areas. SpringerVerlag, Berlin.

Parolo G, Rossi G, Ferrarini A. 2008. Toward improved species niche modelling: Arnica montana in the Alps as a case study. Journal of Applied Ecology 45:1410-1418.

Pearson RG, Raxworthy CJ, Nakamura M, Townsend PA. 2007. Predicting species distributions 
Peterson AT, Ball LG, Cohoon KP. 2002. Predicting distributions of Mexican birds using ecological niche modelling methods. Ibis 144:E27-E32.

Phillips SJ, Anderson RP, Schapire RE. 2006. Maximum entropy modeling of species geographic distributions. Ecological Modelling 190:231-259.

Phillips SJ, Dudík M. 2008. Modeling of species distributions with Maxent: new extensions and a

Pulliam HR. 2000. On the relationship between niche and distribution. Ecology Letters 3:349-361.

R Development Core Team. 2015. R: A language and environment for statistical computing. R Foundation for Statistical Computing, Vienna, Austria. Available at http://www.Rproject.org/.

Rahman AF, Sims DA, Cordova VD, El-Masri BZ. 2005. Potential of MODIS EVI and surface temperature for directly estimating per-pixel ecosystem C fluxes. Geophysical Research Letters 32:

Raxworthy C, Martínez-Meyer E, Horning N, Nussbaum R, Schneider G, Ortega-Huerta M, Peterson AT. 2003. Predicting distributions of known and unknown reptile species in Madagascar. Nature 426:837-841.

Requena-Mullor JM, López E, Castro AJ, Cabello J, Virgós E, González-Miras E, Castro H. 2014. Modeling spatial distribution of European badger in arid landscapes: an ecosystem functioning approach. Landscape Ecology 29:843-855. 
493

494

495

496

497

498

499

500

501

502

503

504

505

506

507

508

509

510

511

512

513

Roberge JM, Angelstam P. 2004. Usefulness of the umbrella species concept as a conservation tool. Conservation Biology 18:76-85.

Rowland MM, Wisdom MJ, Suring LH, Meinke CW. 2006. Greater sage-grouse as an umbrella species for sagebrush-associated vertebrates. Biological Conservation 129:323-335.

Shen Y, Li B, Xiang Y. 2010. Searching the Chinese monal after the earthquake. The Nature (6):79. (in Chinese)

Shepard DB, Kuhns AR, Dreslik MJ, Phillips CA. 2008. Roads as barriers to animal movement in fragmented landscapes. Animal Conservation 11: 288-296.

Stamps JA, Buechner M, Krishnan V. 1987. The effects of edge permeability and habitat geometry on emigration from patches of habitat. American Naturalist 533-552.

Swanepoel LH, Lindsey P, Somers MJ, Hoven Wv, Dalerum F. 2013. Extent and fragmentation of suitable leopard habitat in South Africa. Animal Conservation 16:41-50.

Swets JA. 1988. Measuring the accuracy of diagnostic systems. Science 240:1285-1293.

Tobón-Sampedro A, Rojas-Soto OR. 2015. The geographic and seasonal potential distribution of the little known Fuertes's Oriole Icterus fuertesi. Bird Conservation International 25:489502.

Tuanmu MN, Vina A, Roloff GJ, Liu W, Ouyang ZY, Zhang HM, Liu JG. 2011. Temporal transferability of wildlife habitat models: implications for habitat monitoring. Journal of Biogeography 38: 1510-1523.

Warren DL, Seifert SN. 2011. Ecological niche modeling in Maxent: the importance of model complexity and the performance of model selection criteria. Ecological Applications 
21:335-342.

515 Warren DL, Glor RE, Turelli M. 2010. ENMTools: a toolbox for comparative studies of 516 environmental niche models. Ecography 33:607-611.

517 Warren DL, Wright AN, Seifert SN, Shaffer HB. 2014. Incorporating model complexity and 518 spatial sampling bias into ecological niche models of climate change risks faced by 90 California vertebrate species of concern. Diversity and Distributions 20:334-343.

With KA, Crist TO. 1995. Critical thresholds in species' responses to landscape structure. Ecology 76:2446-2459.

Zhang T. 1995. Distribution and ecology of Chinese monals in Baishuijiang nature reserve Gansu. Chinese Journal of Zoology 30:25-28. (in Chinese) 


\section{Table 1. Sources of Chinese monal presence data in the Qionglai Mountains used in the}

\section{5 suitable habitat modeling.}

\begin{tabular}{|c|c|c|c|c|}
\hline \multirow{3}{*}{ Source } & Elevational range and & Survey technique & \multirow{3}{*}{ Survey time } & \multirow[t]{2}{*}{ Used/total } \\
\hline & & & & \\
\hline & area of survey site & and effort & & presence points \\
\hline \multirow[t]{2}{*}{ Global Biodiversity Information } & & Bird-watching & & \\
\hline & Network database & & $2005-2015$ & $2 / 7$ \\
\hline \multirow[t]{2}{*}{ Facility (http://www.gbif.org/) } & & records & & \\
\hline & $3,300-4,170 \mathrm{~m} ; 35$ & Published & Apr-Nov, & \\
\hline \multirow{2}{*}{ Shen et al. 2010} & & & & $7 / 7$ \\
\hline & $\mathrm{km}^{2}$ & literature & $2007-2010$ & \\
\hline \multirow[t]{2}{*}{ Comprehensive scientific survey } & $1,638-3,868 \mathrm{~m} ; 110$ & Line transect; 29 & Apr-Oct, & \\
\hline & & & & $3 / 3$ \\
\hline on Anzihe Nature Reserve & $\mathrm{km}^{2}$ & $3-4.9 \mathrm{~km}$ transects & 2010 & \\
\hline \multicolumn{5}{|l|}{ Comprehensive scientific survey } \\
\hline & $1,000-4,896 \mathrm{~m} ; 403$ & Line transect; 38 & May-Oct, & \\
\hline \multirow{2}{*}{ on Fengtongzhai National } & & & & $15 / 28$ \\
\hline & $\mathrm{km}^{2}$ & $2-5 \mathrm{~km}$ transects & 2010-2011 & \\
\hline \multicolumn{5}{|l|}{ Nature Reserve } \\
\hline \multicolumn{5}{|l|}{ Sympatric animal database of } \\
\hline & $1,000-4,400 \mathrm{~m} ; 8,740$ & Grid square; 4,370 & Mar-Dec, & \\
\hline \multirow[t]{2}{*}{ the fourth national survey on } & & & & $22 / 24$ \\
\hline & $\mathrm{km}^{2}$ & $2 \mathrm{~km}^{2}$ squares & $2012-2013$ & \\
\hline \multicolumn{5}{|l|}{ giant panda } \\
\hline \multirow[t]{2}{*}{ Infrared-triggered camera } & & Infrared-triggered & All year & \\
\hline & $1,520-4,234 \mathrm{~m} ; 234$ & & & \\
\hline \multirow[t]{2}{*}{ monitoring in Heishuihe Nature } & & camera; 70 & round, 2013- & $5 / 15$ \\
\hline & $\mathrm{km}^{2}$ & & & \\
\hline Reserve & & cameras & 2014 & \\
\hline Infrared-triggered camera & $1,500-4,500 \mathrm{~m} ; 170$ & Infrared-triggered & All year & $4 / 5$ \\
\hline
\end{tabular}


monitoring in Labahe Nature

Reserve

$$
\mathrm{km}^{2}
$$

camera; 30

cameras round, 2014-

2015
Montane bird survey in Wolong

National Nature Reserve
3,600-4,400 m; 17

$\mathrm{km}^{2}$
Line transect; 72 -

$6 \mathrm{~km}$ transects
Jun-Jul,

2015 
527 Table 2. Relative importance of environmental variables in the habitat suitability model of

528 the Chinese monal

529 Note: bioclim17: precipitation of the driest quarter, bioclim5: maximum temperature of the

530 warmest month, d_resident: distance to residential location, evi base value: annual base level value 531 of EVI, evi maximum: annual maximum EVI, d_road: distance to roads.

\begin{tabular}{lll}
\hline Variables & Percent contribution $^{\mathrm{a}}$ & Jackknife of AUC $^{\mathrm{b}}$ \\
\hline bioclim17 & 36.2 & 0.856 \\
bioclim5 & 31.0 & 0.840 \\
d_resident & 10.5 & 0.771 \\
evi base level & 8.8 & 0.689 \\
evi maximum & 6.0 & 0.683 \\
slope & 4.8 & 0.631 \\
d_road & 2.7 & 0.642 \\
\hline
\end{tabular}

532 a The relative contribution of each variable to predictive model, shown as mean value of 20 533 replicates.

534 b Jackknife test of variable importance, expressed as AUC (area under the receiver operating 535 characteristic curve) for models using each variable alone. A higher gain indicates a variable with 536 more information for modelling when used in isolation, shown as mean value of 20 replicates. 
537 Table 3. Estimates of suitable habitat areas of the Chinese monal distributed in counties 538 within the Qionglai Mountains

\begin{tabular}{|c|c|c|c|}
\hline \multirow{3}{*}{ County } & \multirow{3}{*}{ County area $\left(\mathrm{km}^{2}\right)$} & \multirow{3}{*}{$\begin{array}{l}\text { Suitable habitat } \\
\text { area }\left(\mathrm{km}^{2}\right)\end{array}$} & \multirow{3}{*}{$\begin{array}{l}\text { Proportion of } \\
\text { suitable habitat (\%) }\end{array}$} \\
\hline & & & \\
\hline & & & \\
\hline Wenchuan $^{\mathrm{a}}$ & 3,589 & 852 & 23.74 \\
\hline Baoxing & 3,124 & 544 & 17.41 \\
\hline Lixian & 4,325 & 401 & 9.27 \\
\hline Xiaojin & 5,568 & 235 & 4.22 \\
\hline Lushan & 1,259 & 159 & 12.60 \\
\hline Tianquan & 2,390 & 150 & 6.28 \\
\hline Dayi & 1,207 & 80 & 6.63 \\
\hline Kangding ${ }^{\mathrm{b}}$ & 1,666 & 37 & 2.22 \\
\hline Chongzhou $^{\mathrm{a}}$ & 803 & 19 & 2.37 \\
\hline Luding $^{\mathrm{b}}$ & 647 & 13 & 2.00 \\
\hline Qionglai & 1,377 & 0 & 0 \\
\hline Dujiangyan $^{\mathrm{a}}$ & 303 & 0 & 0 \\
\hline Total & 26,258 & 2,490 & 9.48 \\
\hline
\end{tabular}

$539{ }^{a}$ Wenchuan, Dujiangyan and Chongzhou described here are only their west parts of Min River.

$540 \quad \mathrm{~b}$ Kangding and Luding described here are only their east parts of Dadu River. 
541 Table 4. Estimates of suitable habitat areas of the Chinese monal in nature reserves

\begin{tabular}{|c|c|c|c|}
\hline \multirow{2}{*}{ Nature reserve } & Reserve area & Suitable habitat & Proportion of suitable \\
\hline & $\left(\mathrm{km}^{2}\right)$ & area $\left(\mathrm{km}^{2}\right)$ & habitat (\%) \\
\hline Wolong & 2,124 & 585 & 27.54 \\
\hline Miyaluo & 1,951 & 181 & 9.28 \\
\hline Heishuihe & 325 & 146 & 44.92 \\
\hline Siguniangshan & 583 & 131 & 22.47 \\
\hline Caopo & 517 & 128 & 24.76 \\
\hline Fengtongzhai & 403 & 111 & 27.54 \\
\hline Labahe & 239 & 69 & 28.87 \\
\hline Anzihe & 110 & 18 & 16.36 \\
\hline Jintangkongyu & 242 & 0 & 0 \\
\hline Zhailong & 204 & 0 & 0 \\
\hline Total & 6,698 & 1364 & 20.36 \\
\hline
\end{tabular}


543 Figure 1. Topographic map of the Qionglai Mountains, showing the location of the 64 544 presence points of the Chinese monal used in modeling

545 The black triangle shows the location of Huayan tunnel at which we observed monals

546 crossing the road daily (detailed in Discussion). The geographic range of Chinese monal was

547 delineated based on Lu (2015). 


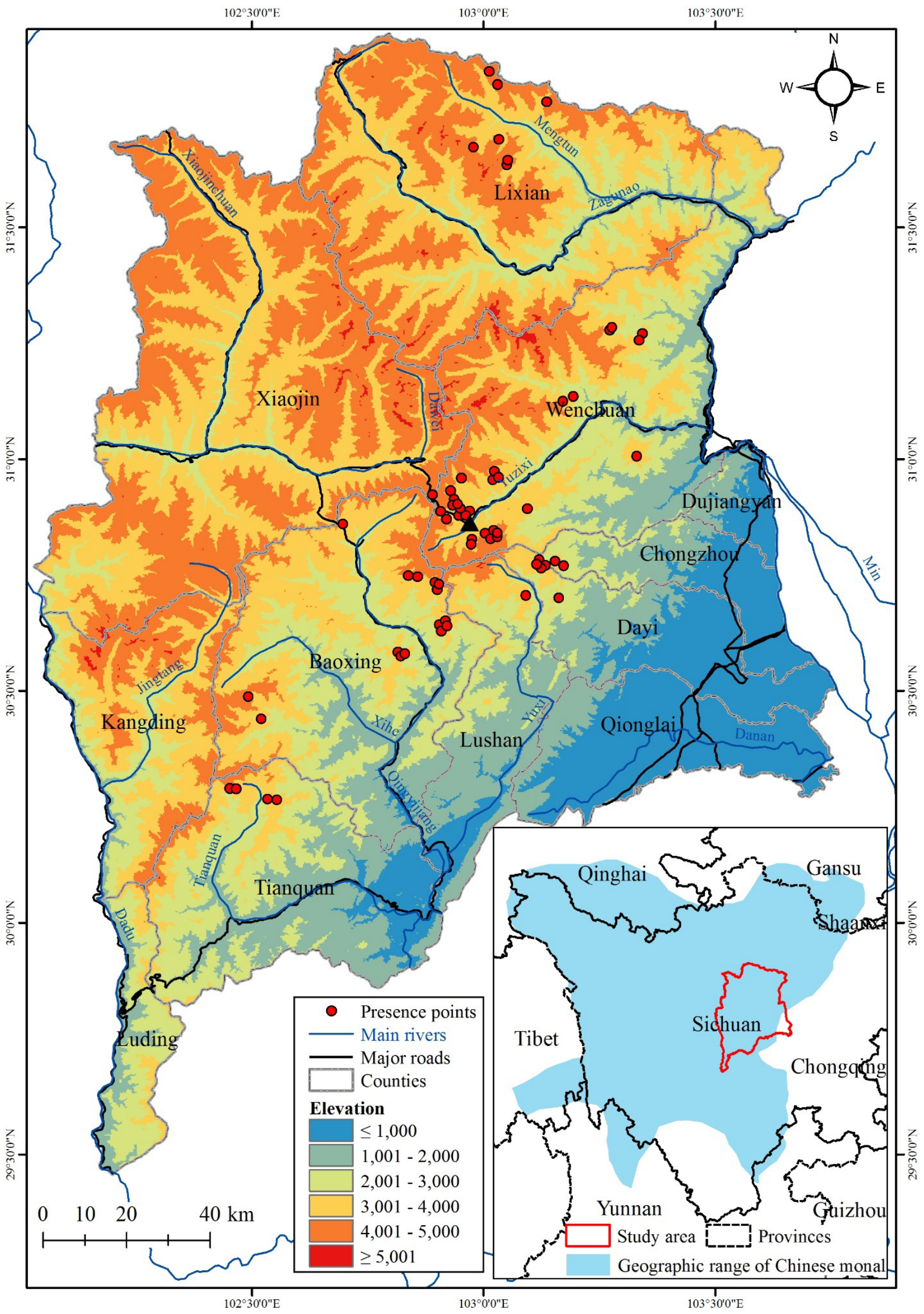


549 Figure 2. Response curves of habitat suitability for the Chinese monal (vertical axis) to the 550 precipitation of the driest quarter (a), maximum temperature of the warmest month (b), 551 distance to residential locations (c), and distance to roads (d).

552 The red lines illustrate the mean responses of 20 replicates and the blue shades showed the 553 +/- standard deviation.
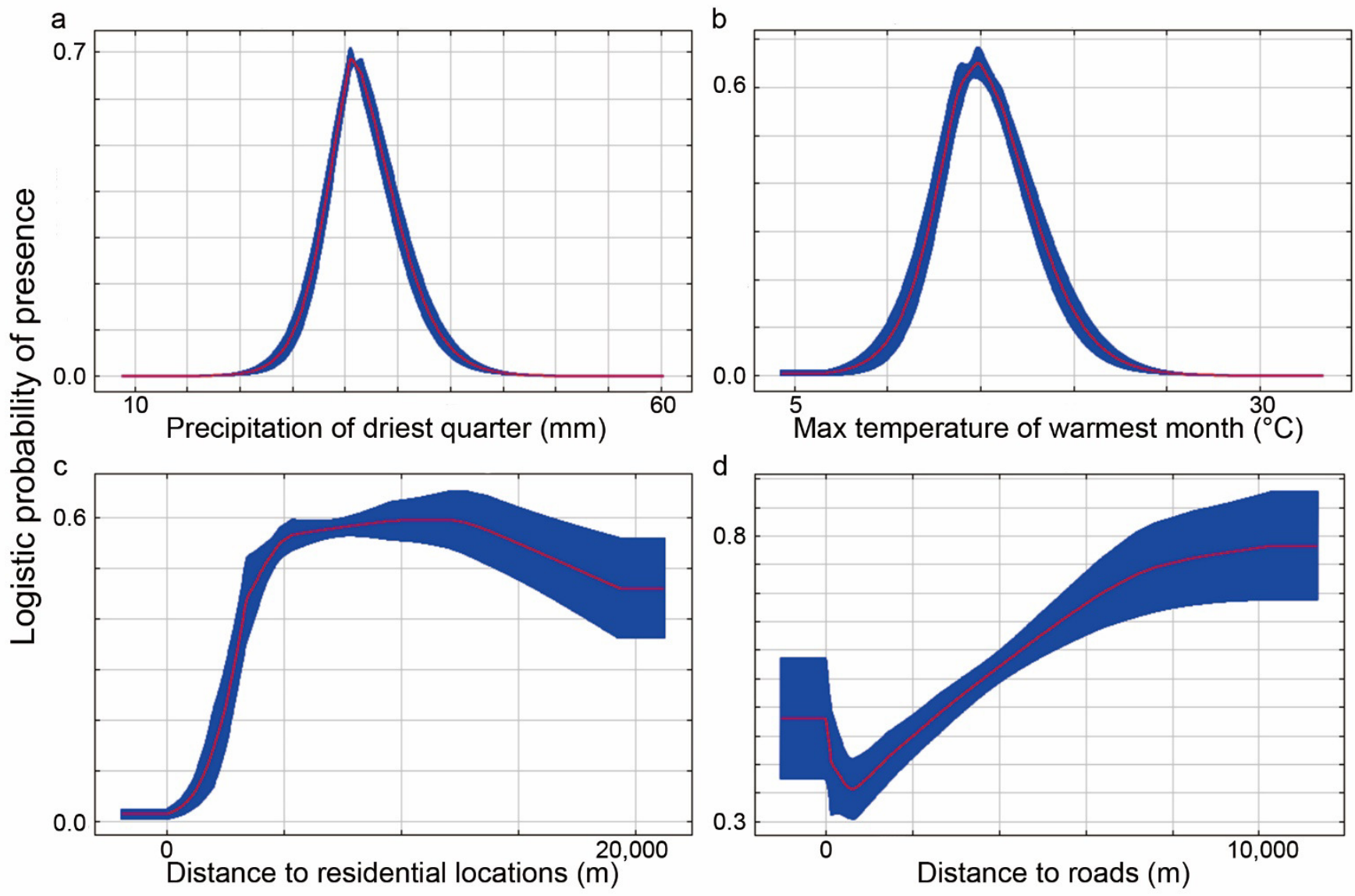
555 Figure 3. Predicted suitable habitat for the Chinese monal and existing nature reserves in 556 the Qionglai Mountains

557 The geographic range of Chinese monal was delineated based on Lu (2015). 


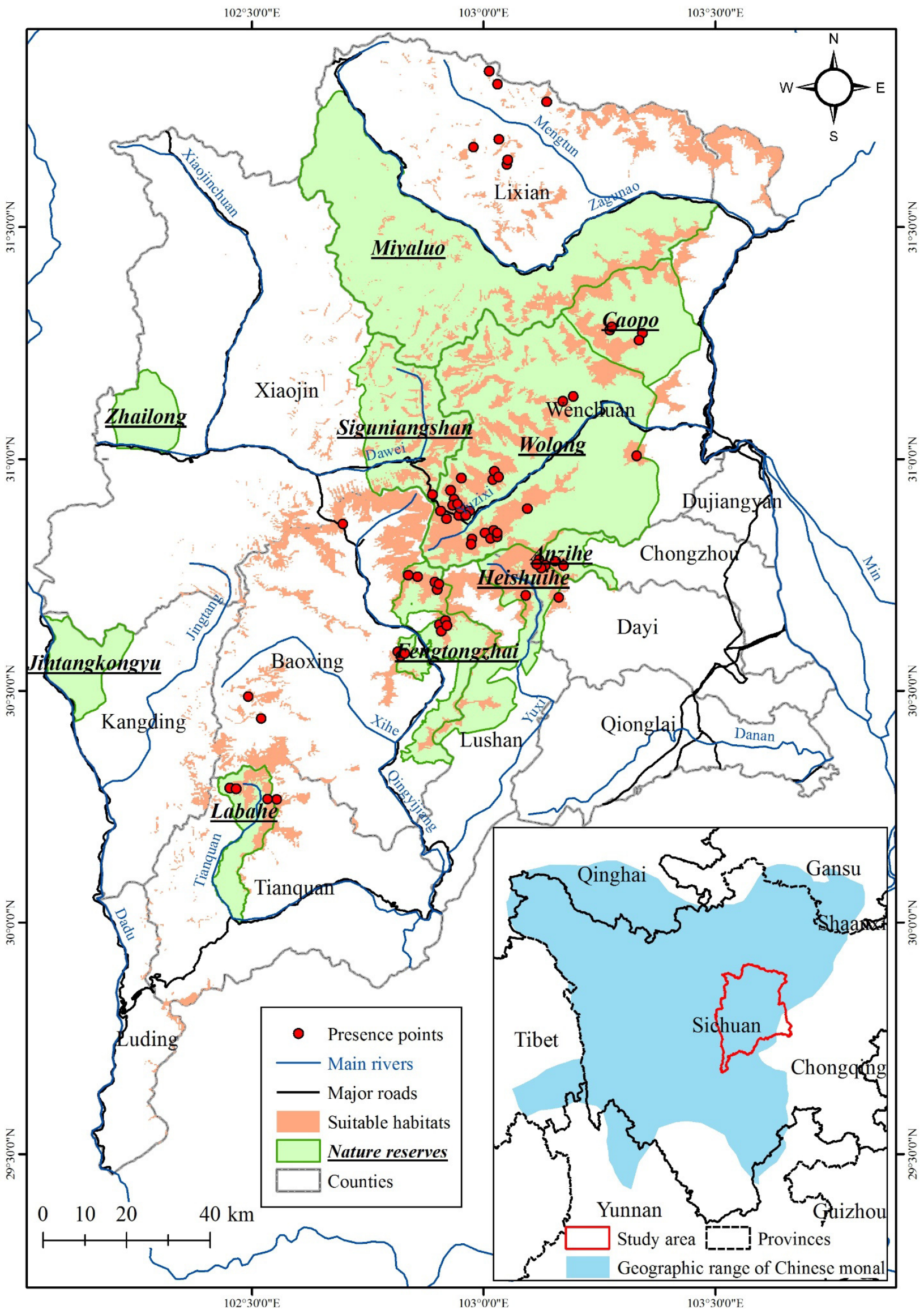

